\title{
POUNDING PROBLEMS IN URBAN AREAS
}

\author{
Chandra Sekhara Reddy $\mathbf{T}^{\mathbf{1}}$, Kiran Kumar Reddy $\mathbf{K}^{2}$, Pradeep Kumar $\mathbf{R}^{3}$ \\ ${ }^{I}$ Professor at G. Pulla Reddy Engineering College, Kurnool, Andhra Pradesh, India \\ ${ }^{2}$ Post Graduate student at G. Pulla Reddy Engineering College, Kurnool, Andhra Pradesh, India. \\ ${ }^{3}$ Professor at IIIT, Hyderabad, India \\ E-mails: tcsreddy61@gmail.com; kkr15691@gmail.com ; ramancharla@iiit.ac.in
}

\begin{abstract}
Buildings in urban areas and metropolitan cities are constructed very close to each other. This is because of the requirement of functional usage and high land value. Because of the insufficient gap between the adjacent buildings or adjacent units of the same buildings, they are most vulnerable for seismic damage like pounding. The adjacent land generally belongs to different land owners, where they construct the buildings for different requirements (residential, public). This leads to different dynamic properties of the adjacent buildings. During the earthquakes these may vibrate in or out-of-phase leading to damages, varying from slight architectural damages to severe structural damages.

In this paper the pounding analysis is done for different cases of different building positions like buildings of same height and same floor level to buildings in row, are analyzed using SAP (2000) software package. When the two buildings are placed at different floor levels the impact force is more than buildings with the same floor levels. Also when buildings are in a row exterior building suffers more pounding damage than the interior building.
\end{abstract}

Keywords: Seismic damage, Dynamic properties, Impact force.

\section{INTRODUCTION}

In urban areas buildings are built very close to each other for proper usage of high valuable land and proper connectivity to adjacent blocks. Adjacent buildings are used for different functional requirements like one for residential and immediate to it is for public/commercial buildings so they may have different height and mass that leads to different dynamic properties. In case the building with longer span is need to be built it needs expansion joints at regular location, improper connection of different units of the same building also have a chance to pound each of adjacent units during high magnitude of earthquakes. Even though building codes specifies that the separation gap between the buildings is required to avoid the pounding between the buildings, many of the land owners are not come forward to follow those regulations. This leads slight architectural failure to severe structural damages during the strong ground motion or by any vibration like bomb blast near to the building site. The main aim of this paper is to analyze the seismic response (pounding force) between the buildings which are constructed without sufficient seismic gap.

\section{OBJECTIVE}

From the past earthquake reports it is shown that pounding damage may lead to structural damages in buildings and in bridges. The objective of this study is to found the impact force due to seismic pounding between the different height buildings when the buildings are inadequately separated at rest position. The pounding force between the buildings when buildings are in located in a series with different height is also done by using SAP2000. The impact force between the adjacent buildings are observed when the two adjacent buildings floor levels are at same level (floor-tofloor) and the floor levels of adjacent buildings are at different levels mainly floor to mid column level and buildings in a row with same floor levels.

\section{OCCURANCE OF POUNDING DAMAGE}

When earthquakes occur in areas of where the buildings are constructed very close to each other without proper separation gap, the buildings may vibrate in out-of-phase motion that lead to hammering of adjacent buildings. The following are some of the places where pounding damage will take place when high magnitude of earthquake is occurred.

(i) Adjacent buildings are constructed at same height and same floor levels with different dynamic properties.(ii)Adjacent buildings are constructed with same height and different floor levels. (iii) Adjacent buildings are constructed with different height and same floor levels. (iv) Adjacent buildings are constructed with different height and different floor levels. (v) Buildings in a row constructed each building of different height and having same floor levels. (vi) buildings in a row constructed each building of different height and different floor levels. (vii) Adjacent units of the same building which are improperly connected by expansion joints.

1. Pounding is the one of the considerable damage types during the earthquake; it is the main cause of severe damages in the adjacent buildings during the earthquakes. The pounding led to non-structural damage to buildings 
(like cracks to masonry walls) to severe damage till collapse of the buildings. Seismic pounding between the adjacent buildings occur during the following cases

(i) During an earthquake of high magnitude

(ii) Adjacent buildings having different dynamic properties

(iii) Buildings which are inadequately separated at rest position

(iv) Adjacent buildings vibrate in out of phase vibrations.

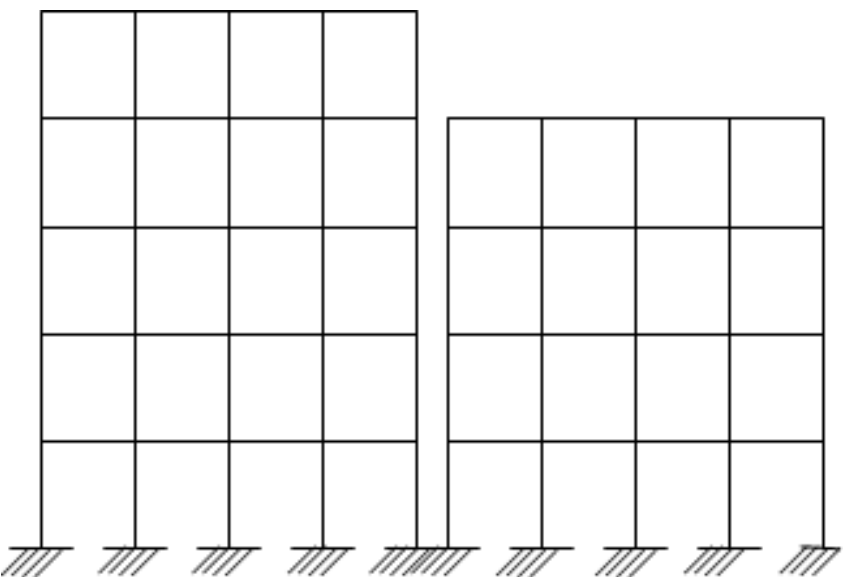

Fig 1 Adjacent buildings with same floor levels but different heights

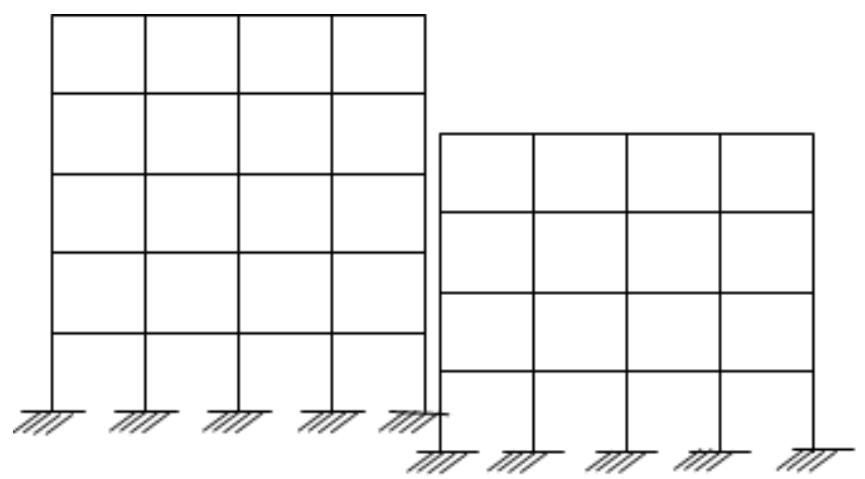

Fig 2 Adjacent buildings with different height and different floor levels
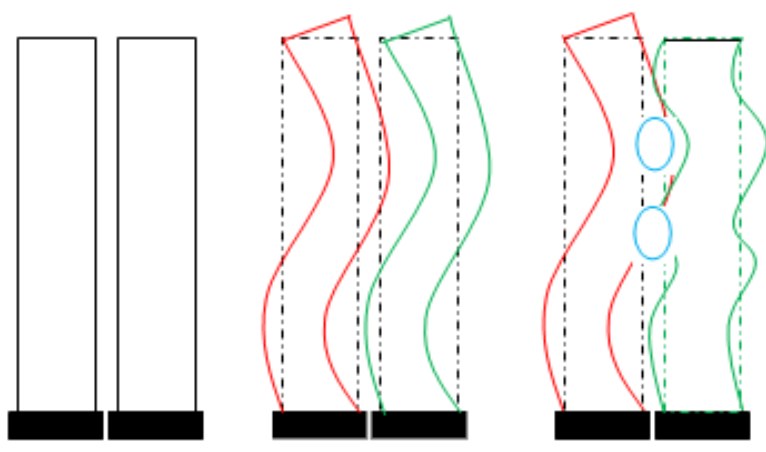

Fig 3 Seismic behavior of adjacent buildings

Required Seismic separation distance to avoid pounding: Bureau of Indian Standards specifies in its code "IS 4326:1993 "Indian Standard Code of Practice for Earthquake Resistant Design and Construction of Buildings (Second Revision)" clause 3.1 states that a separation gap of specified width between the adjacent buildings or different parts of the same building either left uncovered or covered suitably to permit movement in order to avoid hammering due to earthquake. This code mentions separation gap to be provided to avoid pounding between adjacent buildings as in following table

Table 1 Gap width for adjoining structures

\begin{tabular}{|l|l|l|}
\hline SI.No. & Type of Constructions & $\begin{array}{l}\text { Gap width/storey ,in } \\
\mathrm{mm} \mathrm{for} \mathrm{Design} \\
\text { Seismic Coefficient } \\
\alpha \mathrm{h}=0.12\end{array}$ \\
\hline 1 & $\begin{array}{l}\text { Box system or frames } \\
\text { with shear walls }\end{array}$ & 15.0 \\
\hline 2 & $\begin{array}{l}\text { Moment resistant } \\
\text { reinforced concrete frame }\end{array}$ & 20.0 \\
\hline 3 & $\begin{array}{l}\text { Moment resistant steel } \\
\text { frame }\end{array}$ & 30.0 \\
\hline
\end{tabular}

Note- Minimum total gap shall be $25 \mathrm{~mm}$. For any other value of $\alpha \mathrm{h}$ the gap width shall be determined proportionately.

IS 1893 (part 1):2002 "Indian standard Criteria for Earthquake Resistant Design Of Structures, part 1 General Provisions and buildings,(Fifth Revision)" mentioned that ,two adjacent buildings or two adjacent units of the same building with a separation gap shall be separated by a distance equal to $\mathrm{R}$ times the sum of the storey displacements to avoid damaging contact when they deflect towards each other, when floor levels of two adjacent units of same building or buildings are at the same floor levels factor $\mathrm{R}$ in this requirement may replaced by $\mathrm{R} / 2$.

Gap Element Model: To study the impact force between the adjacent buildings of different floor levels, these are connected with gap elements. The gap elements of compression type are chosen to model the pounding. Gap elements are used to connect the two adjacent building models to model the contact between different floor levels. These gap elements which are connected at each adjacent building nodes are become active when the two adjacent buildings are come towards each other i.e. the buildings when vibrate out of phase vibrations and deactivate when the two adjacent nodes are move away(i.e. tension phase). The impact force is measured when the buildings are towards each other more than the gap placed between the building models. The gap elements is activate when the gap become zero in the below figure.

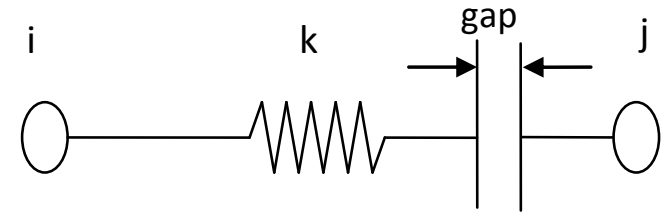

Fig 4 gap element model

The stiffness of the gap element is generally adopted as $10^{2}$ to $10^{4}$ time the stiffness of the adjacent connected element it is taken from the literature. The linear analysis is performed based on the linear stiffness and damping ratio of the gap element. 
The force-deformation relationship is

$$
f=\left\{\begin{array}{cc}
k(d+\text { gap }), & \text { if }(d+\text { gap })<0 \\
0 & \text { otherwise. }
\end{array}\right.
$$

\subsection{Buildings with Same Height and Same Floor}

\section{Levels:}

For the purpose of analysis 5-storey buildings are considered. The floor levels of each 5-storey building are kept at same level. Even though the heights are same the loading on two buildings are different so the dynamic properties of two buildings are different.

\section{Building geometry}

The floor height of the building is $3.0 \mathrm{~m}$ and beams are of $0.3 \mathrm{~m} \times 0.45 \mathrm{~m}$, columns are $0.45 \mathrm{~m} \times 0.45 \mathrm{~m}$ the slab thickness of building is $0.12 \mathrm{~m}$. The total height of both the buildings is $15 \mathrm{~m}$. The properties are same for both the buildings.

\section{Material properties}

The concrete used is M25, steel used is FE415 and the position's ration is 0.2 for both building 1 and building 2 .

The separation between the buildings is kept $0.05 \mathrm{~m}$. Buildings are modeled in SAP2000 and the non-linear time history analysis is performed by giving the Northridge ground motion. As the buildings are of same height and same floor levels and loading are same so the building are having same dynamic properties (time period, frequency). If the two structures are having same dynamic properties they never collide even if there is no separation between them because two structures are move in phase. So in this case two structures are even though having same configuration the loading on two structures are kept different. The live load on building 2 is five times more than the building 1.so the two building are having different dynamic properties.

The main purpose for of connecting two buildings by gap elements is that the gap elements transmit the impact force through the link when the two buildings are come towards each other and contact occurs such that the gap between buildings is closed.

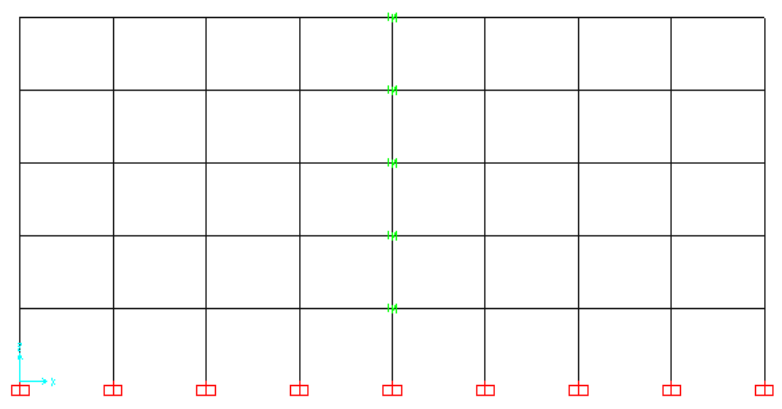

Fig 4 building 1 and building 2 elevation view with gap elements.
The impact force is maximum at the roof node as the displacements are maximum at the top node. The below figure represents impact force at the roof joint.

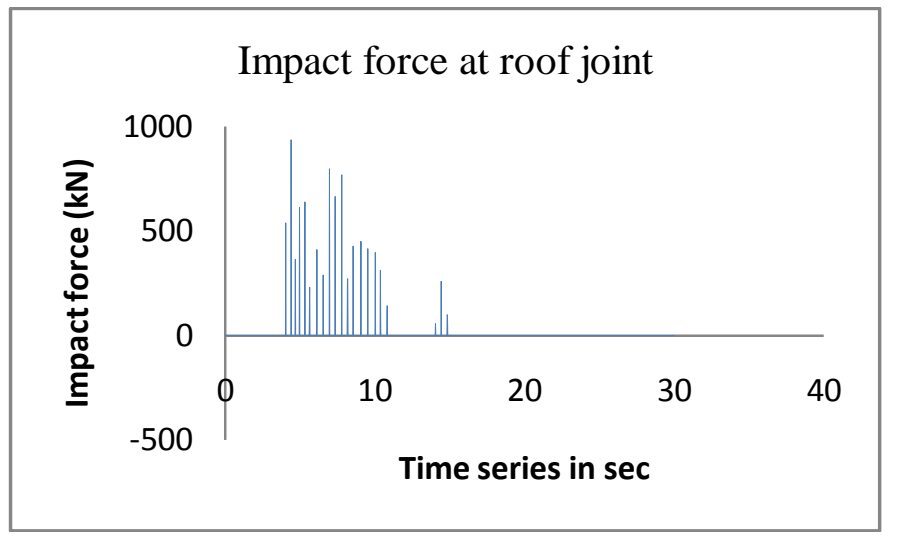

Fig 5 Impact force at the roof joint

The maximum impact force observed is $934 \mathrm{kN}$ at roof joint and the impact force is decreasing gradually to the $1^{\text {st }}$ floor level.

\subsection{Buildings with Same Height but Different Floor}

\section{Levels:}

In these section two adjacent buildings of same height of 5storey and the floor levels of two buildings are different. The floor level of one building is connected to the adjacent building mid-column level so that the effect of mid-column pounding is studied. Two adjacent buildings of 5-storey each are considered. The floor height of the building is 3.0 $\mathrm{m}$ and beams are of $0.3 \mathrm{~m} \times 0.45 \mathrm{~m}$, columns are $0.45 \mathrm{~m} \times$ $0.45 \mathrm{~m}$ the slab thickness of building is $0.12 \mathrm{~m}$. The total height of both the buildings is $15 \mathrm{~m}$. The properties are same for both the buildings.

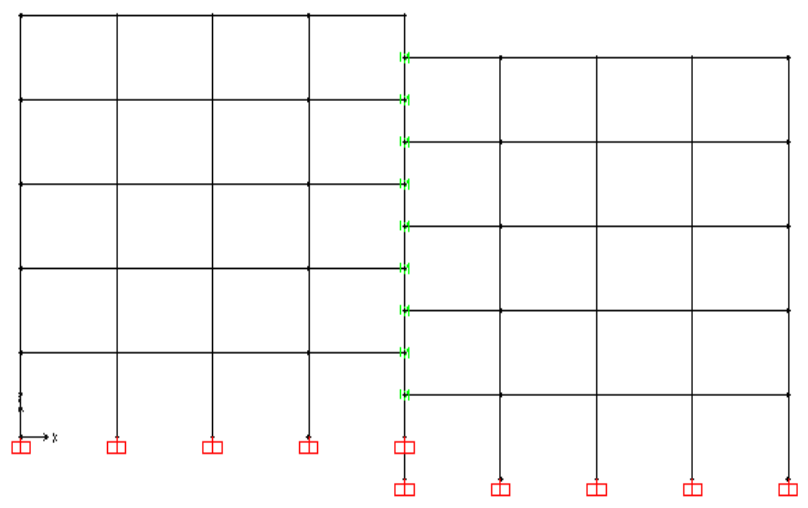

Fig 6 Buildings with same height but different floor levels elevation view.

The impact force between the adjacent buildings is known from the gap elements connected at each storey levels. The gap element at the roof of building 2 has more pounding force as the displacements at the roof of buildings is more the compressive force in the gap element is more. The impact force varies from roof level to the first floor level it is decreases from roof to $1^{\text {st }}$ floor level. 


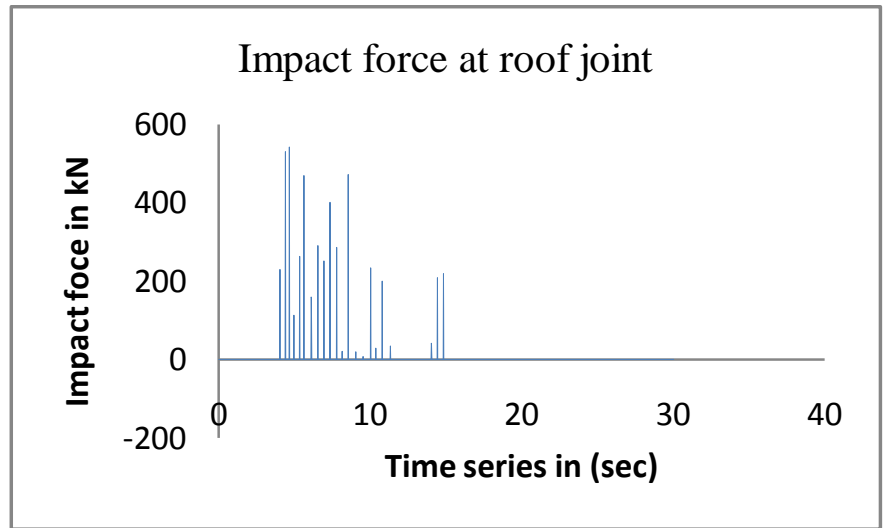

Fig 7 Impact force at roof joint

The maximum impact force observed is $542 \mathrm{kN}$ at roof joint and the impact force is decreasing gradually to the $1^{\text {st }}$ floor level. Even though impact force is minimum compared with adjacent buildings with same heights and same floor levels this type of pounding lead to maximum damage because here impact force is directly affect the columns but in first case slab is there to resist lateral force due to adjacent building impact.

\subsection{Buildings with Different Height and Same Floor}

\section{Levels:}

Two different configurations of buildings like 5-storey building on left side and building adjacent to this is 4-storey building on right side is considered for analysis to study the seismic response (impact force) of buildings subjected to earthquake ground motion. The two adjacent buildings are separated by a distance of $0.05 \mathrm{~m}$. Modeling of structures is done using SAP2000.

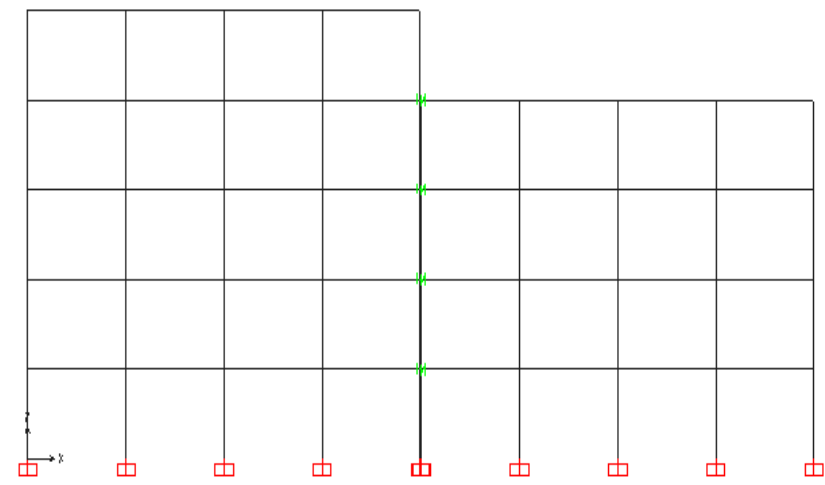

Building 1

Building 2

Fig 8 adjacent buildings with different height but same floor levels elevation view.

The time period of two buildings is $0.389 \mathrm{sec}$ for left side 5storey building and $0.328 \mathrm{sec}$ for right side 4-storey building. The buildings are connected by gap elements with a gap of $0.05 \mathrm{~m}$. The model is subjected to a ground motion of Northridge earthquake measure at Newhall horizontal90. This model is analyzed by nonlinear time history. The impact force due to ground motion between the buildings is maximum of $1736 \mathrm{kN}$ at the top node of 4-storey building. As the displacements are maximum at the roof the impact force is maximum at that location. The displacement responses of two buildings before and after collision are as shown in figure below.

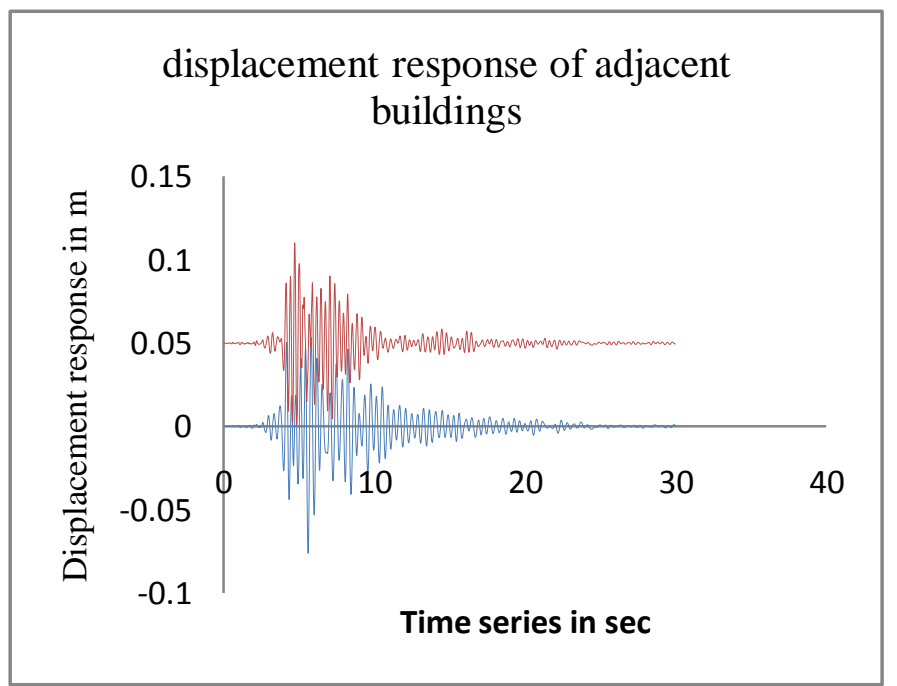

Fig 9 Displacement responses of adjacent buildings with 5 $\mathrm{cm}$ separation gap

The maximum impact force at the roof joint of building 2 is $1736 \mathrm{kN}$ and this impact force is gradually decreased from roof level to the 1 st floor level.

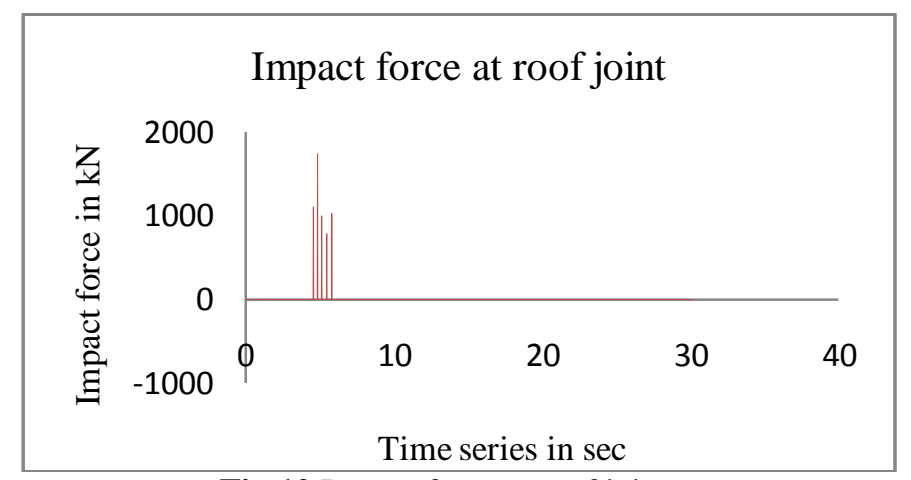

Fig 10 Impact force at roof joint

\subsection{Buildings with Different Heights and Different}

\section{Floor Levels (Floor-Mid Column):}

In this case two adjacent buildings are of different heights i.e. one building is 5-storey and adjacent to it is 4-storey building, two buildings have different foundation levels, and it is considered that the floor of one building is levels to mid-column location of the adjacent building. The two buildings are separated by a separation gap of $0.05 \mathrm{~m}$, are modeled in SAP2000. 


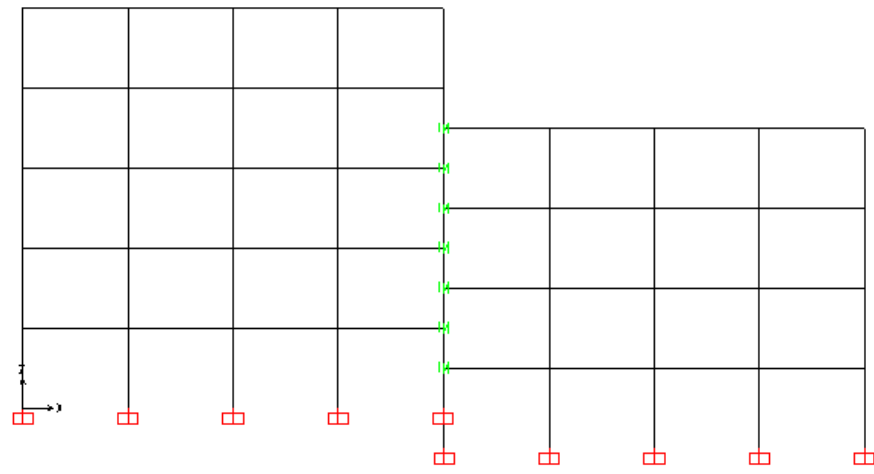

Fig 11 Adjacent buildings with different height and different floor levels

The connection between the buildings is modeled using gap elements with a gap of $0.05 \mathrm{~m}$ this model is subjected to a ground motion which is recorded at Newhall horizontal90 of Northridge ground motion. The impact force in gap element connected at the roof level is $1493 \mathrm{kN}$. The displacement response two buildings before collision and after collision, impact force in the gap element are represented as shown in figure below.

The maximum impact force at the roof joint of building 2 is $1493 \mathrm{kN}$ and this impact force is gradually decreased from roof level to the 1 st floor level. This type of pounding case also lead to severe damage in adjacent buildings as this lateral force resisting elements is columns only.

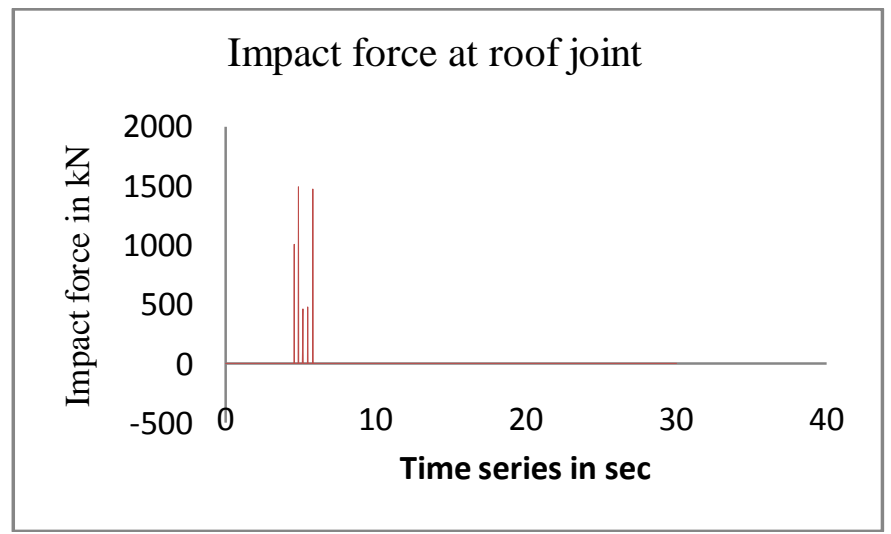

Fig 12 Impact force at roof joint of building 2

Table 2 Impact force between different cases of buildings

\begin{tabular}{|c|c|c|}
\hline \multicolumn{2}{|l|}{ Building position } & Pounding force \\
\hline \multirow[b]{2}{*}{$\begin{array}{l}\text { Buildings with } \\
\text { equal heights }\end{array}$} & $\begin{array}{l}\text { Same height and } \\
\text { same floor levels }\end{array}$ & $934 \mathrm{kN}$ \\
\hline & $\begin{array}{l}\text { Same height but } \\
\text { different floor } \\
\text { levels }\end{array}$ & $542 \mathrm{kN}$ \\
\hline \multirow{2}{*}{$\begin{array}{l}\text { Buildings with } \\
\text { different heights }\end{array}$} & $\begin{array}{l}\text { Different height } \\
\text { but same floor } \\
\text { levels }\end{array}$ & $1736 \mathrm{kN}$ \\
\hline & $\begin{array}{l}\text { Different height } \\
\text { and different floor } \\
\text { levels }\end{array}$ & $1493 \mathrm{kN}$ \\
\hline
\end{tabular}

\subsection{Pounding Analysis of Row of Buildings with} Different Height but Same Floor Levels:

Buildings which are constructed in a row without proper sufficient seismic gap between them are vulnerable to seismic pounding during the earthquakes. To analyze the seismic behavior four different height buildings are considered like 5-storey, 4-storey and 3-storey buildings are considered. These buildings are modeled in SAP2000.the each building in a row is connected by a gap element to measure the impact force between the buildings.

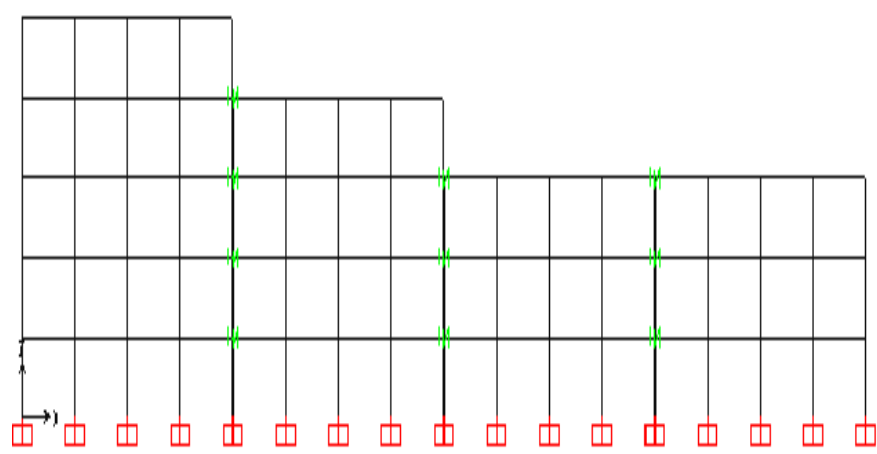

Fig 13 Elevation of buildings in a row with same floor levels and different heights

The above configuration of row of buildings is subjected to Northridge ground motion. The displacement response and the impact forces between the buildings are as shown in figure. From the graphs it is observed that the impact force is maximum at the exterior buildings and the severity of pounding force is less compared to exterior building pounding. This is because the exterior building experiences more displacement than the interior building so the compressive force in the gap element is more.

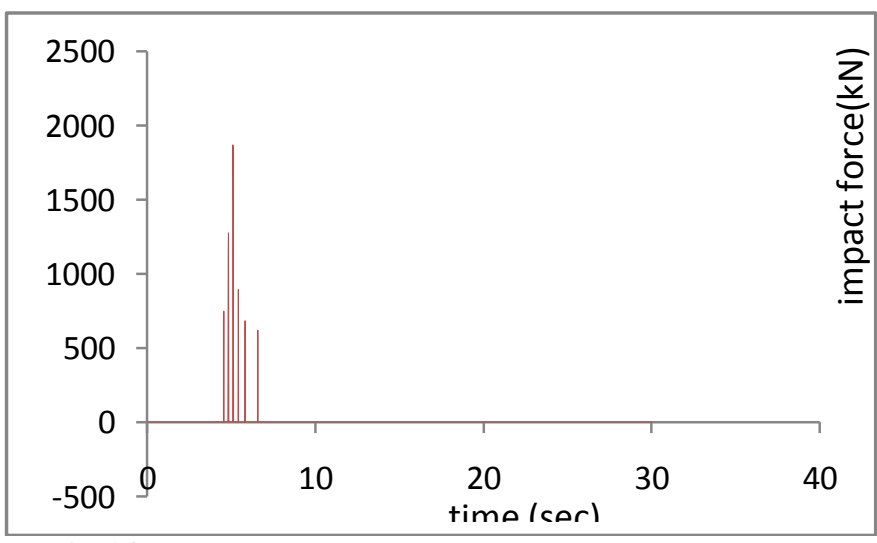

Fig 14 Impact force between the left exterior buildings 


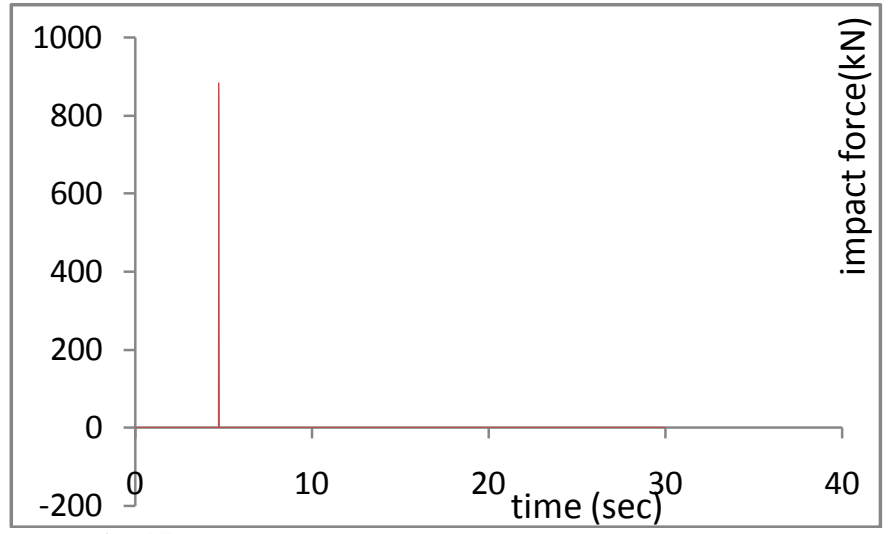

Fig 15 Impact force between the interior buildings

\subsection{Pounding Analysis of Series of Buildings with}

\section{Different Height and Different Floor Level (Floor-}

\section{Mid Column):}

Generally buildings in a series are constructed with different height and different floor levels, depending on the foundation depth, floor height requirements the buildings in a series are comes under this category of building with different height and different floor levels.

The seismic response of the buildings constructed in a row is obtained when they are subjected to Northridge ground motion(PGA is $0.583 \mathrm{~g}$ ). The impact force in the gap elements connected at each floor levels of the all buildings is observed.

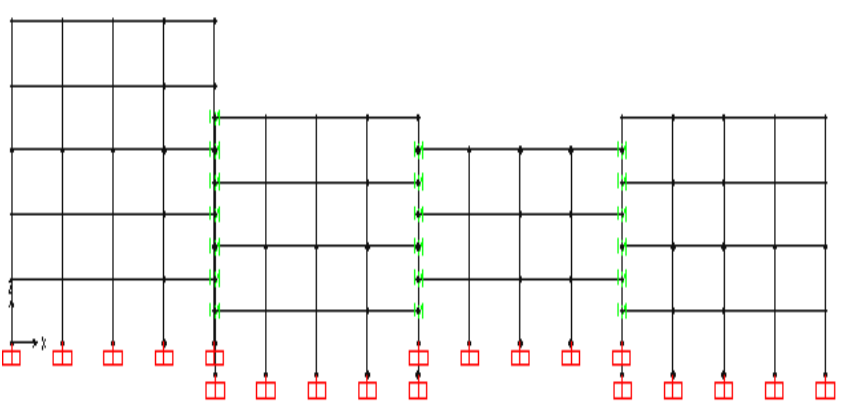

Fig 16 Elevation of buildings with different height and different floor levels in a row.

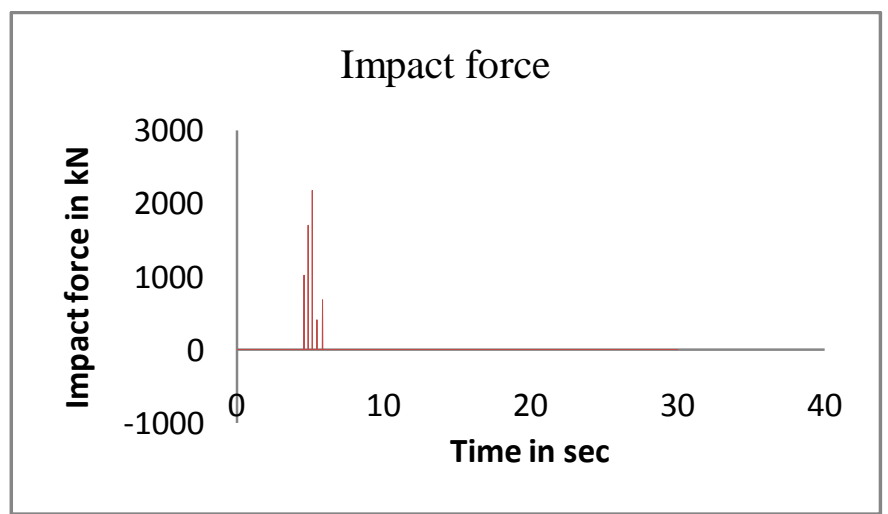

Fig 17 Impact force between left exterior buildings

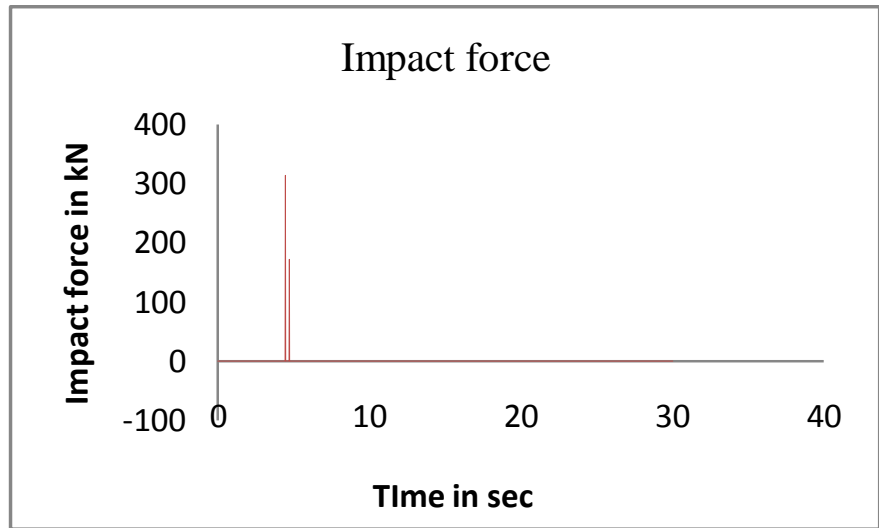

Fig 18 Impact force between interior buildings

The impact force between the left adjacent buildings i.e. 5 storey building and 4 storey building is $2179 \mathrm{kN}$. This is maximum impact force in this series of buildings as the left exterior buildings are heavy structures compared to the right exterior buildings and buildings on extreme side are free to displace so the impact force are more. The impact force in the interior buildings i.e.4 storey building and 3 storey building is $315 \mathrm{kN}$ this is minimum impact force. The impact force in the right exterior buildings is $980 \mathrm{kN}$ this is less as compared to the left exterior buildings because these buildings are small compared to left exterior buildings. This is concluded that the exterior buildings suffer more pounding damage than the interior buildings.

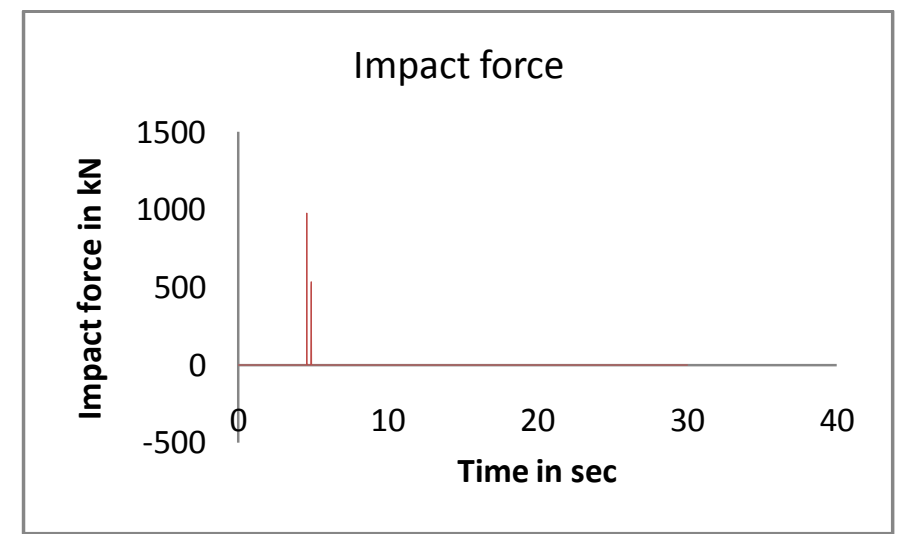

Fig 19 Impact force between right exterior buildings

\section{CONCLUSION}

The impact force between adjacent buildings lead to local damage cracks to severe damage like failure of structural members and it is hazardous for buildings. The conclusions regarding pounding effect (impact force) are as follows:

- $\quad$ The adjacent buildings without proper separation gap are affected by pounding damage during strong earthquakes.

- The buildings with different floor levels are undesirable as the total lateral force (impact force) is directly upon column elements only in this case maximum damage is occurred.

- It is preferable to construct adjacent buildings with same floor level and with suitable separation gap by considering dynamic analysis to avoid pounding. 
- Generally buildings suffer pounding damage when two buildings having different dynamic properties and vibrate in out of phase vibrations.

- When the buildings are in a row, exterior buildings suffer maximum damage compared to the interior buildings.

\section{REFERENCES}

[1] IS 1893 (part 1):2002 "Indian standard Criteria for Earthquake Resistant Design Of Structures, part 1 General Provisions and buildings,(Fifth Revision)".

[2] IS 4326:1993 "Indian Standard Code of Practice for Earthquake Resistant Design and Construction of Buildings (Second Revision)".

[3] Rajaram C, Pradeep Kumar R. Study on Impact Between Adjacent Buildings: Comparison of Codal Provisions.15th WCEE. Report No:IIIT/TR/2012/-1.

[4] D.E Beskos, S.Efraimiadou, G.D.Hatzigeorjiou "Structural Pounding Between Adjacent Buildings: the effects of different structures configurations and multiple Earthquakes. 15th WCEE (2012).

[5] "Mid-Column Seismic Pounding of Reinforced concrete Buildings in a row considering effects of soil" by Kabir Shakya, Anil C.wijeyewickrema. 14th WCEE (2008).

[6] "Earthquake-induced pounding between equal height buildings with substantially different dynamic properties" by Robert Jankowski. Elsevier Engineering structures 30 (2008). 